\title{
ANÁLISE DA MINUTA DE PROJETO DE RESOLUÇÃO DE DIRETRIZES CURRICULARES NACIONAIS PARA O CURSO DE EDUCAÇÃO FÍSICA E A QUESTÃO DA FORMAÇÃO PARA A DOCÊNCIA NA EDUCAÇÃO BÁSICA
}

\author{
Anegleyce Teodoro Rodrigues \\ Universidade Federal de Goiás, Goiânia, Goiás, Brasil \\ Adriane Corrêa da Silva \\ Universidade Federal do Acre, Rio Branco, Acre, Brasil \\ Fabiano Bossle \\ Universidade Federal do Rio Grande do Sul, Porto Alegre, Rio Grande do Sul, Brasil \\ José Angelo Gariglio \\ Universidade Federal de Minas Gerais, Belo Horizonte, Minas Gerais, Brasil \\ Marcos Garcia Neira \\ Universidade de São Paulo, São Paulo, São Paulo, Brasil \\ Wilson Alviano Júnior \\ Universidade Federal de Juiz de Fora, Juiz de Fora, Minas Gerais, Brasil
}

\begin{abstract}
Resumo
O objetivo desse artigo é analisar a proposta de unificação da formação de professores de Educação Física. A problematização questionou se a proposta do Conselho Nacional de Educação (CNE), de Minuta de Diretrizes Curriculares Nacionais (DCN) para o curso de graduação em Educação Física, Licenciatura, de 2015, qualifica a formação para o magistério na Educação Básica. O método de investigação utilizado foi a análise de documentos, que comparou a Minuta com as DCN de Formação de Professores e com as DCN para os cursos de Graduação em Educação Física. Conclui-se que há divergências e contradições de finalidades e princípios entre os documentos quanto à integralidade, terminalidade e identidade própria no campo da formação de professores de Educação Física para a Educação Básica.
\end{abstract}

Palavras-chave: Formação de professores de Educação Física. Diretrizes Curriculares. Educação Básica. Educação Física Escolar.

\section{Introdução}

O presente artigo tem como finalidade contribuir com o debate acerca da proposta de unificação da formação de professores de Educação Física (EF). Inicialmente, apresenta-se uma breve contextualização dos fatos mais recentes que motivaram a ação do CNE em propor novas DCN de graduação com habilitação única de licenciatura. A problematização põe como objeto de reflexão a seguinte questão: o "Projeto de Resolução" em pauta qualifica a formação para o magistério em EF escolar? 
Para discutir essas questões foram analisados alguns documentos, tais como as DCN de Formação de Professores, de 2002 e de 2015, as DCN para os cursos de Graduação em EF, de 2004, e a proposta de Minuta de DCN para o curso de graduação em EF, Licenciatura, de 2015 , dentre outros.

O contexto que motivou o CNE a apresentar tal projeto está ligado à decisão do Superior Tribunal de Justiça (STJ) que julgou, no dia 12 de novembro de 2014, o Recurso Repetitivo, segundo CBCE (2016), em que se discutiam os limites de atuação dos profissionais de EF, decidindo pelo "[...] entendimento, já majoritário dos TRFs e pacífico no Rio de Janeiro, de que licenciados em Educação Física, formados à luz da res. CNE 001/2002, só podem trabalhar com Educação Básica." (CORRÊA, 2014, p.1).

A partir de então, o Conselho Regional de EF, CREF-7/GO, proíbe o exercício profissional em academias, clubes e demais ambientes não formais para os licenciados. Sob o argumento de que tais profissionais passam a ser considerados em exercício ilegal da profissão, a ação fiscalizatória e punitiva do conselho ameaçou o emprego de, aproximadamente, 1800 pessoas no estado de Goiás, que reagiram imediatamente (CBCE, 2016).

Destaca-se que até setembro de 2014, os licenciados em EF estavam autorizados pelo Ministério Público de Goiás e Tocantins a exercerem a profissão em ambientes não formais, como clubes, hotéis e academias, afirmando a inconstitucionalidade da restrição ao trabalho para o licenciado, de acordo com o artigo $5^{\circ}$ da Constituição. Em um clima de tensão e indignação o movimento de organização de professores licenciados em EF contra as ações do sistema CREF/CONFEF ganhou muitos aliados entre as universidades e academias de ginástica, advogados, estudantes, professores, pesquisadores e entidades como o Colégio Brasileiro de Ciências do Esporte (CBCE) (CBCE, 2016).

A partir de janeiro de 2015, o movimento passa a exigir uma posição do CNE por considerar que as atuais DCN de formação de professores ao terem promovido a fragmentação em dois cursos, licenciatura e bacharelado deram a base legal que fundamentou a decisão do STJ. Nesse sentido a interpretação jurídica foi a de que só com a unificação das diretrizes pelo CNE, seria possível reverter a decisão do STJ em benefício da ampla atuação profissional na área. Em dezembro do mesmo ano, o CNE apresenta, então, a proposta de Minuta na tentativa de dar uma solução para tais conflitos (CBCE, 2016).

\section{Integralidade, terminalidade e identidade própria dos Cursos de Licenciatura}

A perspectiva apontada pelas DCN para a formação de professores enfatiza a necessidade de construção de desenhos curriculares para os cursos de formação inicial que rompam com a desarticulação entre formação específica e pedagógica ou pela justaposição destas duas dimensões. A materialização dessa perspectiva de organização curricular dos cursos de formação inicial deveria ter especial preocupação com dois pontos fundamentais: modelos de formação orientados pelo primado do conteúdo específico e o estabelecimento de uma nova relação com a prática docente.

Sobre o primeiro ponto, entende-se que é a partir do conteúdo específico que o tratamento pedagógico deve ser desenvolvido. Enquanto as unidades acadêmicas específicas das Instituições de Ensino Superior não assumirem como responsabilidade própria a formação de professores, muito pouco poderá fazer as unidades da educação. Do ponto de vista conceitual, parte-se do conteúdo específico para se trabalhar a dimensão pedagógica. Assume-se que a liderança deve ser da área específica em colaboração com as unidades de formação (CANDAU, 1997). Os professores em formação precisam conhecer os conteúdos definidos nos currículos da educação básica, pelo desenvolvimento dos quais serão responsáveis, as didáticas próprias de cada conteúdo e as pesquisas que as embasam. É necessário tratá-los de modo articulado, o que significa que o estudo dos conteúdos da educação básica que irão en- 
sinar deverá estar associado à perspectiva de sua didática e aos seus fundamentos. O que parece é que tem se dado grande ênfase à transposição didática dos conteúdos, sem sua necessária ampliação e solidificação - pedagogismo, ou se dá atenção quase que exclusiva aos conhecimentos que o estudante deveria aprender - conteudismo. Desconsideram-se a relevância e a relação com os conteúdos que o futuro professor deverá ensinar nas diferentes etapas da educação básica, segundo o Parecer CNE/CP/09/2001 (BRASIL, 2001).

Atrelado a esse primeiro ponto, a Res. $\mathrm{CNE} / \mathrm{CP} / \mathrm{n}^{\circ} 1 / 2002$ orienta que a prática, na matriz curricular dos cursos de formação inicial, não poderá ficar reduzida a um espaço isolado, que a restrinja ao estágio, desarticulado do restante do curso. A prática deverá estar presente desde o início do curso e permear toda a formação do professor e no interior das áreas ou das disciplinas que constituírem os componentes curriculares de formação, e não apenas nas disciplinas pedagógicas, todas terão a sua dimensão prática. A orientação prevista nas diretrizes curriculares é de que a experiência de prática docente seja um eixo fundamental da formação inicial. Segundo Diniz-Pereira (2011), o rompimento com modelos de racionalidade técnica de formação profissional - e, por conseguinte, a superação da visão aplicacionista e do discurso prescritivo na formação de professores - representa uma necessidade imprescindível para a superação da crise nos cursos de formação docente no País.

A defesa de uma concepção ao mesmo tempo longitudinal/vertical de relação com a prática docente, prevista na Res. CNE/CP/n ${ }^{\circ}$ 1/2002 (BRASIL, 2002a), se sustenta em duas premissas centrais: ele aprende a profissão no lugar similar àquele em que vai atuar, porém, numa situação invertida. Isso implica que deve haver coerência entre o que se faz na formação e o que dele se espera como profissional. O conceito de simetria invertida contida nas diretrizes curriculares dos cursos de licenciatura ajuda a descrever um aspecto da profissão e da prática de professor, que se refere ao fato de que a experiência como aluno, não apenas nos cursos de formação docente, mas ao longo de toda a sua trajetória escolar, é constitutiva do papel que exercerá futuramente como docente.

A compreensão desse fato evidencia a necessidade de que o futuro professor experimente, como aluno, durante todo o processo de formação, as atitudes, modelos didáticos, capacidades e modos de organização que se pretende venham a ser concretizados em suas práticas pedagógicas. Nesta perspectiva, destaca-se a importância do projeto pedagógico do curso de formação na criação do ambiente indispensável para que o futuro professor aprenda as práticas de construção coletiva da proposta pedagógica da escola em que virá a atuar.

A ênfase na construção de currículos com identidade própria está claramente definida pelas DCN de formação de professores, desde 2002, que diz em seu Art. $7^{\circ}$, inciso IV, que "[...] as instituições de formação trabalharão em interação sistemática com as escolas de Educação Básica, desenvolvendo projetos de formação compartilhados”. (BRASIL, 2002a, p.4).

Ademais, observa-se o reforço a esse direcionamento na medida em que a Prática como Componente Curricular e o Estágio Supervisionado foram propostas tendo como foco a Educação Básica por meio de cursos de licenciatura com identidade própria, de $3.200 \mathrm{~h}$, o que reforça a tendência de identidade, terminalidade e integralidade, específicas que caracteriza também as novas DCN de formação de professores, de acordo com a Resolução CNE/CP n. 2, de $1^{\circ}$ de julho de 2015.

No caso específico da Educação Física, Benites, Souza Neto e Hunger (2008) já haviam salientado que esse mesmo princípio presente na Resolução CNE/CP n. 1/2002 era, na verdade, um grande avanço para a área. Nesse sentido, é preocupante a proposta de minuta que unifica dois projetos com focos diferentes de formação e atuação profissional em uma única diretriz normativa: um na Educação Básica, licenciatura e outro no bacharelado, voltado para a área não formal.

Essa preocupação se evidencia diante da polarização da estruturação dos currículos de licenciatura e bacharelado em EF no Brasil. Os campos de conhecimento denominados de 
biodinâmicos e técnico-instrumental, ligados aos saberes identificadores da área, exercem força hegemônica na estruturação e organização curricular tanto em número de professores, projetos de pesquisa, produção de conhecimento, publicações, quanto na pós-graduação, instância em que se formam os professores que atuarão na graduação (MANOEL; CARVALHO, 2011). Sabe-se que o foco desses campos de saberes não é a Educação Básica e, sim, o treinamento físico e esportivo, a promoção da saúde e o mercado do fitness.

No debate estabelecido, um dos argumentos a favor de uma formação unificada para a área de Educação Física está ligado ao conceito de omnilateralidade (SILVA, 2014; LACERDA, 2014), que se contrapõe à formação unilateral, responsável pela fragmentação dos saberes da área, conforme aponta Manacorda,

A divisão do trabalho condiciona a divisão da sociedade em classes e, com ela, a divisão do homem [unilateralidade]; e como esta se torna verdadeiramente tal apenas quando se apresenta como divisão entre trabalho manual e trabalho mental, assim as duas dimensões do homem dividido, cada uma das quais unilateral, são essencialmente as do trabalhador manual e operário, e as do intelectual. (Manacorda, 2010, p. 85).

Importante lembrar que, segundo o próprio autor, o conceito de omnilateralidade está projetado para uma sociedade sem a divisão do trabalho, dependendo, portanto, da superação da sociedade burguesa para consolidar-se. Sem negar a importância deste debate, nos limitaremos a problematizar a Minuta em questão à luz do conceito exposto. Assim, ao retomarmos o documento, verificamos que em momento algum são oferecidos subsídios para superar a fragmentação da formação, visto que são apontados campos de atuação. Cabe destacar ainda o distanciamento do texto em relação à cultura corporal como objeto de conhecimento da Educação Física, mantendo sua fragmentação em uma formação única. Silva (2014) adverte para tal polifonia ao analisar os pressupostos que consideram distintos objetos para a Educação Física Escolar,

$\mathrm{Na}$ Educação Física escolar no seio desse período histórico, averiguamos proposições teóricas que culminam por uma prática pedagógica que oriente uma formação, também, adaptativa, passiva e unilateral. Encontramos teorizações baseadas no positivismo, na fenomenologia que deram ou ainda dão como objeto de conhecimento da Educação Física, por exemplo, como ciência: do movimento humano (em uma abordagem apenas corporal, ou seja, dicotomizada), da motricidade humana, das atividades corporais, do esporte, etc. Enfim, apenas orientações a-dialética, a-histórica e acrítica. (p.203).

Durante a análise da minuta em questão encontramos pressupostos que coadunam com a denúncia apresentada acima. Desta forma, vemos reforçado o entendimento de Manacorda (2010) em relação à omnilateralidade.

\section{Considerações sobre a proposta de Minuta de unificação da formação em Educação Fí- sica, à luz da Resolução CNE/CP n 2/ 2015 e n7/ 2004}

A Minuta de Projeto de Resolução em discussão diz, no parágrafo único do artigo primeiro, que "Os cursos de Educação Física deverão obedecer, ainda, à Resolução CNE/CP $\mathrm{n}^{\circ}$ 2, de $1^{\circ}$ de julho de 2015" (BRASIL, 2015a). Trata-se do ato legal que "define as Diretrizes Curriculares Nacionais para a formação inicial em nível superior (cursos de licenciatura, cur- 
sos de formação pedagógica para graduados e cursos de segunda licenciatura) e para a formação continuada".

Em seu artigo segundo, a Resolução do CNE para Formação de Professores esclarece e delimita a atuação do egresso nas várias etapas e modalidades da Educação Básica, determinando que:

As Diretrizes Curriculares Nacionais para a Formação Inicial e Continuada em Nível Superior de Profissionais do Magistério para a Educação Básica aplicam-se à formação de professores para o exercício da docência na Educação Infantil, no Ensino Fundamental, no Ensino Médio e nas respectivas modalidades de educação (Educação de Jovens e Adultos, Educação Especial, Educação Profissional e Tecnológica, Educação do Campo, Educação Escolar Indígena, Educação a Distância e Educação Escolar Quilombola), nas diferentes áreas do conhecimento e com integração entre elas, podendo abranger um campo específico e/ou interdisciplinar. (BRASIL, 2015a, p. 03)

O conceito de docência surge na resolução em seu parágrafo primeiro do artigo $2^{\circ}$, de forma ampla, como ação docente, e um [...] processo pedagógico intencional e metódico, envolvendo conhecimentos específicos, interdisciplinares e pedagógicos, conceitos, princípios e objetivos da formação que se desenvolvem na construção e apropriação dos valores éticos, linguísticos, estéticos e políticos do conhecimento [...] (BRASIL, 2015a, p.3).

Tal detalhamento tem a finalidade de explicitar, de forma inequívoca, a Educação Básica como espaço de atuação do egresso dos cursos de licenciatura, conforme verificamos em seu artigo $3^{\circ}$, que afirma que a formação inicial e a formação continuada,

[...] destinam-se, respectivamente, à preparação e ao desenvolvimento de profissionais para funções de magistério na Educação Básica em suas etapas [...] a partir de compreensão ampla e contextualizada de educação e educação escolar, visando assegurar a produção e difusão de conhecimentos de determinada área e a participação na elaboração e implementação do projeto político-pedagógico da instituição, na perspectiva de garantir, com qualidade, os direitos e objetivos de aprendizagem e o seu desenvolvimento, a gestão democrática e a avaliação institucional. (BRASIL, 2015a, p.3).

A resolução ainda ressalta em seu parágrafo segundo do mesmo artigo o seu entendimento de educação:

$\S 2^{\circ}[\ldots]$ se efetiva, de modo sistemático e sustentável, nas instituições educativas, por meio de processos pedagógicos entre os profissionais e estudantes articulados nas áreas de conhecimento específico e/ou interdisciplinar e pedagógico, nas políticas, na gestão, nos fundamentos e nas teorias sociais e pedagógicas para a formação ampla e cidadã e para o aprendizado nos diferentes níveis, etapas e modalidades de Educação básica. (BRASIL, 2015a, p.4)

Em seu parágrafo quarto estabelece a compreensão de profissionais do magistério como $\S 4^{\circ}[\ldots]$ aqueles que exercem atividades de docência e demais atividades pedagógicas, incluindo a gestão educacional dos sistemas de ensino e das unidades escolares de Educação Básica, nas diversas etapas e modalidades de educação [...]. (BRASIL, 2015a, p.4)

Os parágrafos $5^{\circ}$ e $6^{\circ}$ apontam a especificidade da formação para a docência na Educação Básica e a articulação desta com os sistemas, como princípio fundamental dos cursos de Licenciatura. Já os artigos $5^{\circ}, 7^{\circ}$ e $8^{\circ}$ procuram estabelecer um perfil do egresso em termos de 
saberes e intervenção pedagógica de forma detalhada, reforçando como já fora estabelecido no artigo $3^{\circ}$, o campo de atuação do egresso nas várias etapas e modalidades da Educação Básica, o que se confirma no artigo $10^{\circ}$ com o acréscimo da possibilidade de atuação na gestão e no planejamento e coordenação de projetos e/ou atividades de ensino.

Em contraposição à perspectiva de integralidade, terminalidade e identidade própria da formação para a Educação Básica, a leitura da Minuta de Projeto de Resolução que institui as DCN para os cursos de EF, Licenciatura, em seu artigo $5^{\circ}$, parágrafo primeiro, que trata das competências e habilidades a serem desenvolvidas, aponta, em seus incisos III, IV e V, que a formação deve possibilitar ao egresso:

III - intervir acadêmica e profissionalmente de forma deliberada, adequada e eticamente balizada nos campos da prevenção, promoção, proteção e reabilitação da saúde, da formação cultural, da educação e reeducação motora, do rendimento físico-esportivo, do lazer, da gestão de empreendimentos relacionados às atividades físicas, recreativas e esportivas, além de outros campos que oportunizem ou venham a oportunizar a prática de atividades físicas, recreativas e esportivas;

IV - participar, assessorar, coordenar, liderar e gerenciar equipes multiprofissionais de discussão, de definição e de operacionalização de políticas públicas e institucionais nos campos da saúde, do lazer, do esporte, da educação, da segurança, do urbanismo, do ambiente, da cultura, do trabalho, dentre outros;

$\mathrm{V}$ - diagnosticar os interesses, as expectativas e as necessidades das pessoas (crianças, jovens, adultos, idosos, pessoas portadoras de deficiência, de grupos e comunidades especiais) de modo a planejar, prescrever, ensinar, orientar, assessorar, supervisionar, controlar e avaliar projetos e programas de atividades físicas, recreativas e esportivas nas perspectivas da prevenção, promoção, proteção e reabilitação da saúde, da formação cultural, da educação e reeducação motora, do rendimento físico-esportivo, do lazer e de outros campos que propiciem ou venham a propiciar a prática de atividades físicas, recreativas e esportivas, desenvolvidos nos âmbitos de instituições educacionais, de atendimento à saúde e nas demais instâncias sociais pertinentes. (BRASIL, 2015b, p. 2-3)

A Minuta advoga diversos campos de atuação para o egresso dos cursos de Licenciatura em EF e apenas no item IV, do parágrafo $5^{\circ}$ é mencionada a educação, ainda assim em caráter difuso, sem especificar se diz respeito, ou não, à instituição escolar. Ao longo do texto a única referência à Educação Básica se dá no Artigo $9^{\circ}$, parágrafo segundo, onde o documento trata a questão do estágio, que veremos com maior profundidade adiante.

Há que se destacar que as competências e habilidades relacionadas no fragmento acima são exatamente as mesmas da Resolução CNE/CP nº 07/2004, que instituiu "as Diretrizes Curriculares Nacionais para os cursos de graduação em Educação Física, em nível superior de graduação plena". Essa normativa, em ao menos três momentos (artigo $1^{\circ}$, parágrafo $2^{\circ}$, do artigo $4^{\circ}$ e parágrafo $3^{\circ}$, do artigo $6^{\circ}$ ), não deixa dúvidas de que se trata de legislação voltada para o campo de atuação não formal.

Consequentemente, é de se estranhar que uma Minuta de DCN para a licenciatura simplesmente reproduza o perfil desejado para o exercício da profissão em ambientes não formais. Em contrapartida, a atual DCN para Formação de Professores para a Educação Básica defende o aprofundamento da formação em questões voltadas para uma atuação docente sintonizada com as demandas educacionais da sociedade contemporânea (DOURADO, 2015).

Em sentido contrário, a Minuta proposta desconsidera a produção de conhecimentos dos campos sociocultural e pedagógico da EF, ao descaracterizar a cultura corporal como ob- 
jeto do componente curricular e retomar o discurso enunciado na Resolução 07/2004, que elegia a Educação Motora, Prevenção da Saúde e prática de atividades físicas, recreativas e desportivas.

Do ponto de vista das exigências legais em relação ao estágio, um grande desafio seria articular a realidade atual que é composta por dois projetos formativos diferentes em Educação Física, a Licenciatura e o Bacharelado. Considerando o que estabelece a Resolução CNE/CP n. 02 de 2015, não será tarefa fácil, pois, reitera-se que estas diretrizes visam à formação para o exercício da docência nas diferentes etapas e modalidades da Educação Básica. Aspecto que será dificultado tendo em vista a abrangência de campos de saberes e institucionais que deverão ser mobilizados por meio dos currículos das licenciaturas de maneira a incluírem o conhecimento das demandas provenientes das várias etapas e modalidades de ensino, além daquelas provenientes dos estágios dos atuais cursos de bacharelado, como clubes, academias, centros de saúde, hospitais, clínicas e outros.

Todavia, o parágrafo $3^{\circ}$, do artigo $9^{\circ}$ da Minuta exige que apenas $40 \%$ da carga horária de estágio seja cumprida no campo de intervenção acadêmico-profissional correlato. Ademais da carga de estágios, os cursos de licenciatura possuem também 400 horas de prática como componente curricular. Trata-se de atividades distintas, mas que têm como único foco a formação para atuação na Educação Básica (SOUZA NETO; ALEGRE; COSTA, 2006). Tendo em vista a proposta de unificação, o que se pode prever é a divisão das horas de estágio e a diminuição da fundamentação teórica acadêmico-científica geral e pedagógica do futuro professor. Essa suspeita tem como lastro as pesquisas que denunciam as características de muitos currículos que conferem o título de licenciado em Educação Física, mas, na verdade, priorizam os conhecimentos do bacharelado (ALVIANO JÚNIOR, 2011; NUNES, 2011).

No campo do Bacharelado a intervenção está baseada na prevenção, na promoção e reabilitação da saúde, no rendimento físico-desportivo, entre outros, conforme reforça o artigo $2^{\circ}$ da Minuta, absolutamente idêntico ao artigo $3^{\circ}$ da Resolução 07/2004. Por outro lado, na Licenciatura, a identidade da docência se refere ao magistério na Educação Básica, tal como vigora na Resolução 02/2015.

\section{Considerações finais}

O estudo analítico dos documentos mostra que está posta uma forte tensão para o campo acadêmico da Educação Física. Com base nas análises realizadas, muitas questões ficam em aberto. A proposta de formação unificada conseguirá abranger conteúdos de ambos os cursos no campo de estágio e da prática pedagógica? Qual será o parâmetro para definir os campos de atuação desses componentes curriculares? Como dividir a carga horária estabelecida por lei nas duas áreas (Licenciatura e Bacharelado)? A formação será específica na educação escolar ou fora dela, ou ainda em ambas?

Em síntese, das contradições que foram apontadas neste estudo, destaca-se que uma das finalidades do "Projeto de Resolução" é tentar resolver uma situação jurídica conflituosa que se refere ao exercício profissional em ambientes não formais por parte de licenciados em Educação Física, um problema real de caráter social que não deve ser ignorado. Entretanto, a solução proposta pelo CNE, por meio da Minuta, mimetiza a legislação anterior e é repleta de lacunas quando o foco recai em um projeto formativo para a docência na Educação Básica.

\section{DRAFT ANALYSIS OF NATIONAL CURRICULUM GUIDELINES DRAFT RESOLUTION FOR THE COURSE OF PHYSICAL EDUCATION AND THE ISSUE OF TRAINING FOR TEACHERS IN BASIC EDUCATION}




\begin{abstract}
The aim of this paper is to analyze the proposal to unify the training of physical education teachers, provided for in the draft resolution Draft establishing new National Curriculum Guidelines for the undergraduate degree in Physical Education, Bachelor. The research is qualitative, drawing upon the analysis of documents as a single data collection procedure. The article sought to establish comparative between this Draft Resolution, the National Curriculum Guidelines for initial training at the college level (undergraduate courses, teacher training courses for graduates and second-degree courses) and the National Curriculum Guidelines for undergraduate courses in physical education in higher education full graduation. It is concluded that there are differences and purposes of contradictions between the three documents, especially regarding the need for construction of undergraduate courses with its own identity, clearly articulated the challenges of professional intervention of Physical Education teachers in basic education.

Keywords: Physical Education Teachers Training. Curriculum Guidelines. Basic Education. Physical Education School.

\section{ANÁLISIS DE LINEAMIENTOS CURRICULARES NACIONALES PROYECTO DE RESOLUCIÓN PARA EL CURSO DE LA EDUCACIÓN FÍSICA Y EL TEMA DE LA FORMACIÓN DE MAESTROS DE EDUCACIÓN BÁSICA}

\title{
Resumen
}

El objetivo de este trabajo es analizar la propuesta de unificar la formación de los profesores de educación física, previsto en el proyecto de resolución de establecimiento de nuevas Directrices Curriculares Nacionales para la licenciatura en Educación Física, Licenciatura. La investigación es cualitativa, basándose en el análisis de documentos como un único procedimiento de recogida de datos. El artículo trata de establecer comparativo entre este proyecto de resolución, las Directrices Curriculares Nacionales para la formación inicial en el nivel universitario (carreras de grado, cursos de formación de profesores para los graduados y cursos de segundo grado) y las Directrices Curriculares Nacionales para los cursos de graduación en la educación física en la educación superior de la graduación completa. Se concluye que existen diferencias y propósitos de contradicciones entre los tres documentos, especialmente con respecto a la necesidad de construcción de los cursos de graduación con su propia identidad, articulado con claridad los retos de la intervención profesional de los profesores de educación física en la educación básica.

Palabras clave: Formación de profesores de educación física. Lineamientos Curriculares. La educación básica. Escuela de Educación Física.

\section{Referências}

ALVIANO JÚNIOR, W. Formação inicial em Educação Física: análises de uma construção curricular. Tese (Doutorado em Educação) - Faculdade de Educação. Universidade de São Paulo. São Paulo: FEUSP, 2011.

BENITES, L. C.; SOUZA NETO, S.; HUNGER, D. O processo de constituição histórica das diretrizes curriculares na formação de professores de Educação Física. Educação e Pesquisa, São Paulo, v. 34, n. 2, p.343-360, mai-ago 2008. 
BRASIL. Parecer CNE/CP 009/2001. Parecer sobre as Diretrizes Curriculares Nacionais para a Formação de Professores da Educação Básica, em nível superior, curso de licenciatura, de graduação plena. Brasília, 2001.

Resolução CNE/CP n. 1 de, 18 de fevereiro de 2002. Institui Diretrizes Curriculares Nacionais para a Formação de Professores da Educação Básica, em nível superior, curso de licenciatura, graduação plena. Brasília, 2002 a.

Resolução CNE/CP n. 2, de 18 de fevereiro de 2002. Institui a duração e a carga horária dos cursos de licenciatura, de graduação plena, de formação de professores da Educação Básica em nível superior. Brasília, 2002 b.

Resolução CNE/CP n. 7, de 31 de março de 2004. Institui as Diretrizes Curriculares Nacionais para os cursos de graduação em Educação Física, em nível superior de graduação plena. Brasília, 2004.

Resolução CNE/CP n. 2, de $1^{\circ}$ de julho de 2015. Define as Diretrizes Curriculares Nacionais para a formação inicial em nível superior (cursos de licenciatura, cursos de formação pedagógica para graduados e cursos de segunda licenciatura) e para a formação continuada. Brasília, 2015 a.

.CNE/CES. Minuta de Projeto de Resolução para audiência pública de 11/12/2015: Institui Diretrizes Curriculares Nacionais para o curso de graduação em Educação Física, Licenciatura. Brasília, 2015 b.

CANDAU,V.M. Universidade e formação de professores: Que rumos tomar? CANDAU, V.M. (Org.). In: Magistério: construção cotidiana. Petrópolis: Vozes, 1997.

CBCE. Sobre as mudanças das Diretrizes Curriculares da Educação Física: relatório de reflexões em/de GTTs CBCE. 2016. Disponível em: https://www.cbce.org.br/upload/biblioteca/gtts_cbce_dcns_graduacao_ef.pdf . Acesso em: 05/07/2016.

CORRÊA, R. STF Julga recurso repetitivo sobre atuação de licenciado em Educação Física. Rio de Janeiro, 2014. Disponível em: http://profrobertocorrea.blogspot.com.br/2014/12/stj-julga-recurso-repetitivo-sobre.html Acesso em: 05/03/2015.

DINIZ-PEREIRA, J. E. O ovo ou a galinha: a crise da profissão docente e a aparente falta de perspectiva para a educação brasileira. Revista Brasileira de Estudos Pedagógicos, v. 92, p. 34-51, 2011.

DOURADO, L. F. Diretrizes Curriculares Nacionais para a formação inicial e continuada dos profissionais do magistério da Educação Básica: concepções e desafios. Educ. Soc., Campinas, v. 36, nº. 131, p. 299-324, abr.-jun., 2015.

LACERDA, Cristiane Guimarães de. Formação de professores de Educação Física para a Educação Infantil na perspectiva da formação ampliada: contribuições da Pedagogia Histórico-Crítica. 2014. 127 f. Dissertação (Mestrado em Educação) - Faculdade de Educação, Universidade Federal da Bahia, Salvador, 2014. 
MANACORDA, M.A. História da Educação: da antiguidade aos nossos dias. 13 ed. São Paulo. Cortez. 2010.

MANOEL, E. J.; CARVALHO, Y. M. Pós-graduação na educação física brasileira: a atração (fatal) para a biodinâmica. Educação \& Pesquisa, São Paulo, vol.37, n.2, pp.389-406, mai./ago. 2011.

NUNES, M. L. F. Sobre Frankensteins, Monstros e Ben 10: fragmentos da formação em Educação Física. Tese (Doutorado em Educação) - Faculdade de Educação. Universidade de São Paulo. São Paulo: FE-USP, 2011.

SILVA, Matheus Bernardo Contribuições da educação física escolar para formação omnilateral do ser social: uma reflexão à luz da psicologia histórico-cultural e da pedagogia histórico-crítica. 2014. 223 f. Dissertação (Mestrado em Educação) - Setor de Educação, Universidade Federal do Paraná. Curitiba, 2014.

SOUZA NETO, S.; ALEGRE, A. N.; COSTA, A. A prática como componente curricular e o estágio curricular supervisionado: que rumo tomar? In: SOUZA NETO, S.; HUNGER, D. (Orgs.) Formação profissional em Educação Física: estudos e pesquisas. Rio Claro: Biblioética, 2006.

Recebido em: 09/07/2016

Revisado em: 23/09/2016

Aprovado em: 23/09/2016

Endereço para correspondência:

teodoro.fef@gmail.com

Anegleyce Teodoro Rodrigues

Faculdade de Educação Física e Dança

Universidade Federal de Goiás - UFG

Campus Samambaia

Avenida Esperança s/n, Campus Samambaia- CEP: 74.690-900

Goiânia - Goiás - Brasil 